Research Article

\title{
Effects of Climate Variability on Normalized Difference Vegetation Index (NDVI) in the Gojeb River Catchment, Omo-Gibe Basin, Ethiopia
}

\author{
Melku Dagnachew $\mathbb{D}^{1},{ }^{1,2}$ Asfaw Kebede ${ }^{D},{ }^{2}$ Awdenegest Moges $\mathbb{D}^{3},{ }^{3}$ and Adane Abebe ${ }^{4}$ \\ ${ }^{1}$ Natural Resources Management, Wolaita Soddo University, Wolaita Soddo, P.O. Box 138, Ethiopia \\ ${ }^{2}$ Haramaya Institute of Technology, Haramaya University, Dire Dawa, P.O. Box 138, Ethiopia \\ ${ }^{3}$ Hawassa Institute of Technology, Hawassa University, Hawassa, P.O. Box 05, Ethiopia \\ ${ }^{4}$ Arba Minchi Institute of Technology, Arba Minchi University, Arba Minchi, Ethiopia \\ Correspondence should be addressed to Melku Dagnachew; melku1980@gmail.com
}

Received 18 December 2019; Revised 24 January 2020; Accepted 11 February 2020; Published 10 June 2020

Academic Editor: Federico Porcù

Copyright (c) 2020 Melku Dagnachew et al. This is an open access article distributed under the Creative Commons Attribution License, which permits unrestricted use, distribution, and reproduction in any medium, provided the original work is properly cited.

\begin{abstract}
Vegetation dynamics have been visibly influenced by climate variability. The Normalized Difference Vegetation Index (NDVI) has been the most commonly used index in vegetation dynamics. The study was conducted to examine the effects of climatic variability (rainfall) on NDVI for the periods 1982-2015 in the Gojeb River Catchment (GRC), Omo-Gibe Basin, Ethiopia. The spatiotemporal trend in NDVI and rainfall time series was assessed using a Theil-Sen (Sen) slope and Mann-Kendall (MK) statistical significance test at a 95\% confidence interval. Moreover, the residual trend analysis (RESTREND) method was used to investigate the effect of rainfall and human induction on vegetation degradation. The Sen's slope trend analysis and MK significant test indicated that the magnitude of annual NDVI and rainfall showed significant decrement and/or increment in various portions of the GRC. The concurrent decrement and/or increment of annual NDVI and rainfall distributions both spatially and temporarily could be attributed to the significant positive correlation of the monthly $\left(\mathrm{R}_{\mathrm{NDVI}-\mathrm{RF}}=0.189, P \leq 0.001\right)$ and annual ( $\mathrm{R}_{\mathrm{NDVI}}$ $\mathrm{RF}=0.637, P \leq 0.001) \mathrm{NDVI}$ with rainfall in almost all portions of the catchment. In the GRC, a strongly negative decrement and strong positive increment of NDVI could be derived by human-induced and rainfall variability, respectively. Accordingly, the significant NDVI decrement in the downstream portion and significant increment in the northern portion of the catchment could be attributed to human-induced vegetation degradation and the variability of rainfall, respectively. The dominance of a decreasing trend in the residuals at the pixel level for the NDVI from 1982, 1984, 2000, 2008 to 2012 indicates vegetation degradation. The strong upward trend in the residuals evident from 1983, 1991, 1998 to 2007 was indicative of vegetation improvements. In the GRC, the residuals may be derived from climatic variations (mainly rainfall) and human activities. The time lag between NDVI and climate factors (rainfall) varied mainly from two to three months. In the study catchment, since vegetation degradations are mainly caused by human induction and rainfall variability, integrated and sustainable landscape management and climate-smart agricultural practices could have paramount importance in reversing the degradation processes.
\end{abstract}

\section{Introduction}

Vegetation dynamics have been visibly influenced by climate variability due to biophysical responses of plant respiration and photosynthesis $[1,2]$. The remotely sensed Normalized Difference Vegetation Index (NDVI) derived from the Advanced Very-High-Resolution Radiometer (AVHRR) of
National Oceanic and Atmospheric Administration (NOAA) satellite $[3,4]$ has been the most commonly used index in vegetation dynamics $[5,6]$. The NOAA satellites contain AVHRR sensor [7], which collects spectral information in the visible and near-infrared regions, facilitating calculation of the NDVI [8]. The main reasons for using AVHRR-NDVI images in many environmental studies are 
its high temporal and adequate spatial resolution, good calibration, and low price [3]. NDVI is calculated as the difference between near-infrared and visible reflectance values normalized over the sum of the two and ranges from -1 to +1 for a given pixel [8]. Because of high reflectance in the NIR portion of the Electromagnetic Spectrum (EMS), healthy vegetation is represented by NDVI values between 0.1 and 1 . On the contrary, nonvegetated surfaces such as water bodies yield negative values of NDVI. Bare soil areas represent NDVI values which are closest to 0 due to high reflectance in both visible and NIR portions of the EMS [9]. An NDVI value of zero means no vegetation and a value close to $+1(0.8-0.9)$ indicates the highest possible density of green leaves [8].

The NDVI is recognized as a reliable indicator of land cover conditions and variations in a wide range of studies spanning regional to global scales [10]. The growth and distribution of natural vegetation were significantly affected by climate variability at various spatial and temporal scales [11-13]. Rainfall is the most important climatic factors directly affecting vegetation dynamics and closely correlates with NDVI due to its irregularity and seasonal variability $[14,15]$. It is a particularly important predictor of vegetation distribution $[15,16]$.

Many researchers have used NDVI to monitor the response of vegetation to rainfall fluctuations. The strong associations between rainfall and NDVI have been reported in various regions of the world $[8,13,17]$. Several studies have also investigated the relationship between rainfall and NDVI on global and regional scales to demonstrate a very close linkage between them [15, 18]. Furthermore, the correlation results for NDVI and climatic variables from different parts of the world showed a significant relationship between NDVI and precipitation in the northern hemisphere semiarid regions [17]. Al-Bakri and Suleiman [3] obtained a significant positive correlation between NDVI and rainfall for both 10-day and monthly data in the Jordan region. Zhao et al. [19] found a direct association between vegetation growth and rainfall in relatively dry areas while an inverse association in relatively humid areas. Various studies $[3,17,20-22]$ have also found significant correlations between NDVI and rainfall in different regions. Hence, vegetation dynamics and their relationship with climate variability have become a hotspot in global change studies $[21,23]$.

The most widely used global NDVI dataset is the Global Inventory Monitoring and Mapping Studies (GIMMS) database [24]. This dataset is famous for its high quality, having been corrected to remove some nonvegetation effects caused by solar angle and sensor errors. It has been widely used to monitor long-term trends in vegetation activity from regional to global scales [6]. In the Gojeb River Catchment, no studies have been carried out on the performance of the Global Inventory Monitoring and Modelling System (GIMMS3g) in monitoring vegetation dynamics in relation to monthly, seasonal, and annual climate variability in general and rainfall variability in particular. Hence, the aim of this study is to examine the spatiotemporal vegetation dynamics (Normalized Difference Vegetation Index
(NDVI)) and its response to climate variability (rainfall) using GIMMS3g from 1982 to 2015 in Gojeb River Catchment, Omo-Gibe Basin, Ethiopia. The objectives of this study are to (1) investigate the monthly, seasonal, and annual NDVI trend in relation to climate variability in Gojeb River Catchment during the past 34 years; (2) analyze the correlation between NDVI and climatic factors in order to determine the impact of climatic variability in vegetation dynamics at temporal and spatial scales; and (3) distinguish the relative importance of the impacts of climate variability (rainfall) and human activities on vegetation dynamics using wavelet analysis in the Gojeb River Catchment of Omo-Gibe Basin, Ethiopia.

\section{Materials and Methods}

2.1. Description of the Study Area. The study was conducted at the Gojeb River Catchment (GRC), a part of the OmoGibe basin in Ethiopia (Figure 1). The Omo-Gibe basin, third largest perennial river in Ethiopia next to the Baro Akobo and Blue Nile rivers, lies between $5^{\circ} 31^{\prime}$ to $10^{\circ} 54^{\prime} \mathrm{N}$ and $33^{\circ} 0^{\prime}$ to $36^{\circ} 17^{\prime} \mathrm{E}$ and covers about $79,000 \mathrm{~km}^{2}$ of land area in South and Southwest Ethiopia [25]. The GRC is located between $7^{\circ} 00^{\prime}-7^{\circ} 50^{\prime} \mathrm{N}$ latitude and $35^{\circ} 30^{\prime}-37^{\circ} 20^{\prime} \mathrm{E}$ and covers a total area of $6932.345 \mathrm{~km}^{2}$ with altitudinal ranges from 817 to $2500 \mathrm{~m}$.

In the Omo-Gibe River Basin, the climate varies from a hot arid climate in the southern part of the floodplain to a tropical humid in the highlands that include the extreme north and northwestern part of the basin [25]. The rainfall varies from over $1900 \mathrm{~mm}$ per annum in the north-central areas to less than $300 \mathrm{~mm}$ per annum in the south. Moreover, the rainfall regime is unimodal for the northern and central parts of the basin and bimodal for the south. The mean annual temperature in the Omo-Gibe basin varies from $16^{\circ} \mathrm{C}$ in the highlands of the north to over $29^{\circ} \mathrm{C}$ in the lowlands of the south [26]. In the GRC, the rainfall is unimodal and the amount increases with the increase in elevation. The mean annual rainfall of the catchment ranges from $1390.7 \mathrm{~mm}$ in the downstream portion to $1884.0 \mathrm{~mm}$ in the upstream portion. The mean monthly maximum temperature and minimum temperature are 25.9 and $14.4^{\circ} \mathrm{C}$, respectively (Figure 2). The land use pattern is dominated by five land use categories, namely, woodland, cropland/agricultural, swamp, forest, and shrubland [27]. The total population of the catchment is about 2,637,351 of whom $1,320,571(50.07 \%)$ are men and 1,316,780 (49.93\%) are women and while only $9.2 \%$ are urban inhabitants [28].

\subsection{Data Used}

2.2.1. GIMMS3g NDVI Dataset. The Normalized Difference Vegetation Index (NDVI) derived from satellite data is an important indicator that can be used to analyze green vegetation dynamics and reveal the response of vegetation dynamic to the climate variability [7]. NDVI is the most widely used index for monitoring the spatiotemporal dynamics of green vegetation and ecoclimatological studies 


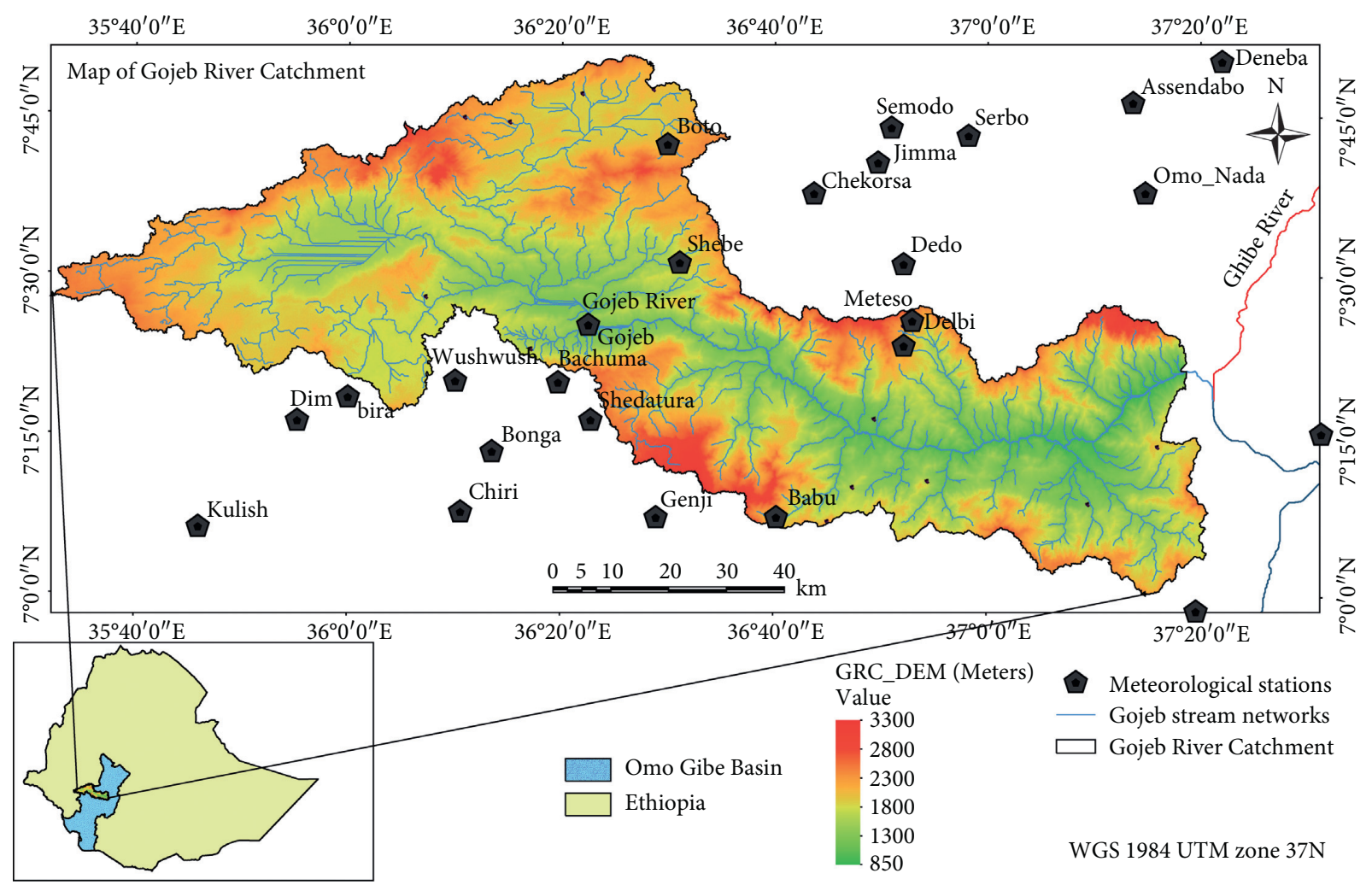

FIgURE 1: Study map of Gojeb River Catchment (GRC), Omo-Gibe Basin, Ethiopia.

$[1,7,29-34]$. The index ranges between -1 (water bodies) and 1 (dense vegetation) [17] and computed as follows [35]:

$$
\mathrm{NDVI}=\frac{\mathrm{NIR}-\mathrm{RED}}{\mathrm{NIR}+\mathrm{RED}}
$$

where NIR and RED denote spectral reflectance in the nearinfrared $(800-1000 \mathrm{~nm})$ and red $(620-750 \mathrm{~nm})$ portions of the electromagnetic spectrum, respectively.

The most commonly used and unique Earth observation program, which enables the analysis of vegetation activity over the past three decades, is provided by the National Oceanic and Atmospheric Administration (NOAA) Polarorbiting satellites [4]. The NOAA satellites contain the Advanced Very-High-Resolution Radiometer (AVHRR) sensor [7, 32], which collects spectral information in the visible and near-infrared regions, facilitating calculation of the NDVI [8]. The NDVI data from NOAA-AVHRR sensors have been widely used to analyze vegetation dynamics and trends in various regions of the world $[5,6]$. The most widely used global dataset of NDVI from NOAA-AVHRR series satellite data is the Global Inventory Monitoring and Mapping Studies (GIMMS) database [24], which covers a longer period than the other available datasets (1981-2015). This dataset is famous for its high quality, having been corrected to remove some nonvegetation effects caused by solar angle and sensor errors, and has been widely used to monitor long-term trends in vegetation activity from regional to global scales [6].

In the Gojeb River Catchment, the NDVI dataset used is the third-generation version acquired from Global
Inventory Modelling and Mapping Studies (GIMMS NDVI3g) available from January 1982 to December 2015. In this study catchment, the NDVI dataset used was the latest updated version of the third-generation Global Inventory Monitoring and Modelling System (GIMMS NDVI3g) $[36,37]$ available at https://ecocast.arc.nasa.gov/data/pub/ gimms/3g.v1/as nc4 files. GIMMS3G NDVI data comprise a long-time series global vegetation index dataset based on NOAA meteorological satellites (NOAA 7, 9, 11, 14, 16, 17, and 18) [32, 36]. Among the long-term AVHRR-based datasets analyzed, the GIMMS3g NDVI is found to have the highest temporal consistency and is the most appropriate choice for NDVI trend analysis [30, 36-39]. The GIMMS NDVI3g is generated from NOAA's AVHRR data, and the spatial resolution is $1 / 12^{\circ}$. Its temporal resolution is 15 -day intervals with 34 years' time span (1982 to 2015). The GIMMS3g NDVI dataset has already been shown to accurately represent the real responses of vegetation to climate variability $[32,36,37,40]$. The quality and consistency of the GIMMS3g data are assured by correction for (i) sensor degradation, (ii) sensor intercalibration differences, (iii) solar zenith and viewing angles, (iv) volcanic aerosols, (v) atmospheric water vapor, and (vi) cloud cover [4]. In the study catchment, a satellite orbital drift correction is performed using an empirical mode decomposition/reconstruction (EMD) method by minimizing the effects of orbital drift by removing common trends between the time series of Solar Zenith Angle (SZA) and NDVI [30, 31, 41].

In the study catchment, due to the ease of accessibility of the dataset, the GIMMS3G NDVI dataset, which spans from 


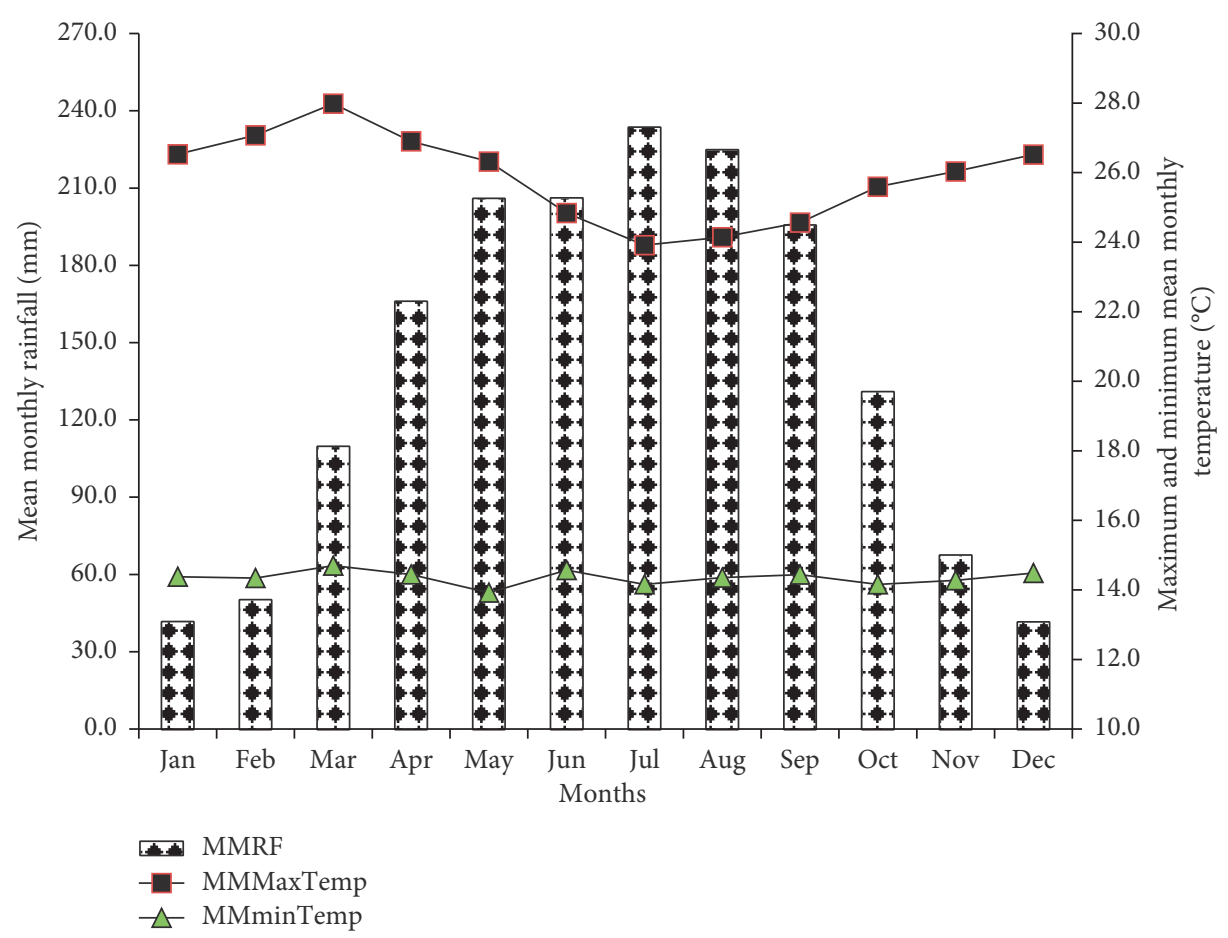

Figure 2: Mean monthly rainfall $(\mathrm{mm})$ and mean monthly maximum and minimum temperature $\left({ }^{\circ} \mathrm{C}\right)$ of Gojeb River Catchment (1982-2015).

January 1982 to December 2015 with a 15-day interval, derived from AVHRR sensors was used. The GIMMS3g NDVI dataset is considered the best dataset available for long-term NDVI trend analysis [36]. The GIMMS3g NDVI dataset has a spatial and temporal resolution of $0.05^{\circ} \times 0.05^{\circ}$ and 15 days, respectively. Nowadays, it is considered as the best dataset available for long-term NDVI trend analysis [42]; it accurately represents the real responses of vegetation to climate variability [40]; it possesses the highest temporal consistency and is appropriate for trend analysis [42]. The biweekly NDVI data were converted into monthly values using the maximum value composite method to reduce cloud disturbance and increase the overall quality of the dataset [30]. A maximum value composite (MVC) method was applied to get the monthly NDVI data by reducing the atmospheric effects of clouds and aerosol [1, 7, 43, 44]. An MVC technique is a process that minimizes cloud contamination, reduces directional reflectance and off-nadir viewing effects, minimizes sun-angle and shadow effects, and minimizes aerosol and water-vapor effects on NDVI signal [45]. The averaged NDVI for Bega (dry season) from December to February (DJF), Belg (small rainy season) from March to May (MAM), Kiremt (main rainy season) from June to August (JJA), and Meher (main harvesting period with moderate rainfall) from September to November (SON) was calculated for analysis. The GIMMS3g NDVI dataset was cut to the extent of Gojeb River Catchment and the bimonthly data are aggregated to monthly, seasonal, and annual composites by applying the arithmetic mean of each month. Finally, the monthly, seasonal, and annual NDVI for the entire study catchment from 1982 to 2015 has been made available.

2.2.2. Rainfall Data. The monthly, seasonal, and annual distribution of rainfall is determinant for vegetation growth and productivity in various ecosystems and widely used to evaluate changes in vegetation dynamics [46]. In order to examine trends in the spatiotemporal variation of rainfall in the catchment, the product of Climate Hazards group Infrared Precipitation with Stations (CHIRPS) time series data from January 1982 to December 2015 was used. The CHIRPS data was created at the United States Geological Survey (USGS) and Earth Resources Observation and Science (EROS) Centre. The CHIRPS data used had a spatial and temporal resolution of $0.05^{\circ} \times 0.05^{\circ}$ degree and one month, respectively. The CHIRPS (v2.0) project provides rainfall datasets based on conjunction geostationary infrared satellite rainfall estimates and rain gauge observations that are interpolated to produce robust precipitation grids [47]. The CHIRPS is updated frequently and provides data at higher spatial and temporal resolutions. It is high quality, temporally consistent, and near real-time precipitation datasets that can help identify environmental changes, quantify the important role played by warming air temperatures, and play an important role in seasonal drought prediction [47, 48]. Monthly gridded precipitation data over the 1982-2015 study periods were downloaded (http://chg.geog. ucsb.edu/data/chirps/) and averaged to match the $0.05^{\circ}$ spatial resolution of NDVI data. 
In the study catchment, NDVI and rainfall analysis was focused on the basis of four seasons, i.e., Bega (dry season) from December to February (DJF), Belg (small rainy season) from March to May (MAM), Kiremt (main rainy season) from June to August (JJA), and Meher (main harvesting period with moderate rainfall) from September to November (SON). The long-term NDVI climatology (1982-2015) was created by averaging data for all cloud-free pixels for DJF, MAM, JJA, and SON for the same period. Then, four seasons were summed on an annual basis between 1982 and 2015 as the independent variable.

2.3. Image Processing. All images were processed in MATLAB version 2016a and 2017b and ArcGIS Version 10.3 and then the NDVI and rainfall datasets were further processed in Microsoft Excel. The raw NDVI data was downloaded and processed following different steps. Firstly, the satellite data was analyzed using remote sensing tools. In ArcGIS, the coordinate system of all images was defined into GCS-WGS1984 and projected into UTM-37N, which is a coordinate system used in the Gojeb River Catchment. The NDVI values were calculated using a raster calculator in ArcGIS 10.3 and MATLAB tools and divided into relevant classes. These classes when converted into spatial data indicated the spatial and temporal changes in vegetation. Secondly, all the images that were refined using ArcGIS and MATLAB tools and clipped using the study catchment boundary shapefile and the mean values of NDVI were extracted for each land cover class. Finally, the mean NDVI values were exported into Microsoft Excel, and graphs were produced to show the monthly, seasonal, and annual patterns of NDVI and rainfall. Moreover, using ArcGIS and MATLAB, different maps were produced to show the spatial and temporal variation of NDVI with respect to rainfall.

In the study catchment, the rainfall data was downloaded in a gridded dataset form for the study periods from January 1982 to December 2015. Firstly, to get the total monthly rainfall for each year, the images were added in MATLAB and ArcGIS tools. Secondly, the coordinate system of all images was defined into GCS-WGS-1984 and projected into UTM-37. Thirdly, all the total monthly rainfall images were clipped using the catchment boundary shapefile and/or Tiff file. Then, the mean value of rainfall was extracted for each land cover class. The mean values were exported into Microsoft Excel for trend analyses and graphs were produced to show patterns of rainfall. As a result, maps were produced to show the spatial and temporal variation of rainfall with respect to NDVI.

\subsection{Data Analysis: Impact of Climate Variable (RF) on} Vegetation Dynamics (NDVI). In the GRC, correlation analysis was carried out using monthly, seasonal, and annual NDVI and rainfall at each grid point to understand the relationship between them. Correlations between NDVI and rainfall were computed using the Pearson correlation method. The coefficient of Pearson enabled the magnitude of each correlation to be measured on a per-pixel basis for the period of 1982-2015. The statistical significance was tested using Pearson's correlation coefficients at a confidence level of $95 \%(P=0.05)$. If the correlation coefficients were greater than $0.3(P=0.05)$, it was considered that NDVI had a strong correlation with rainfall [49]. The significance of the correlation coefficients was mapped to show the spatial distribution of the relationships.

2.4.1. Analysis of Trends of NDVI and Rainfall. The trend in rainfall and NDVI time series was assessed at both spatial and temporal levels during monthly, seasonal (DJF, MAM, JJA, and SON), and annual basis. The trends of the NDVI and rainfall were analyzed using a Theil-Sen (Sen) slope, which is a robust nonparametric statistical estimation of the trend magnitude which is insensitive to small outliers and missing noises values [49]. The magnitude of NDVI and rainfall changes was assessed using Sen's slope at a 95\% confidence interval where positive and negative values indicate increased and decreased in rainfall and vegetation, respectively. Statistical significance of Sen's slope trend was tested using the Mann-Kendall (MK) significance test, which is widely applied to long-time series trend analysis with nonnormal data [49]. The MK test requires the data to be serially independent in order to avoid large uncertainty in estimating the trend of serially correlated data like rainfall and NDVI $[34,50]$. The MK test for assessing trends in both NDVI and rainfall using their detrended data component was used. NDVI time series encompass vegetation seasonal growth in relation to the amount and distribution of rainfall. The MK test is one of the widely used nonparametric tests for assessing seasonal variations mainly in hydrological time series [51, 52]. However, it is currently more commonly applied for testing the significance of changes in NDVI trends $[34,53]$. The MK trend test is less sensitive to missing data values, irregular data distribution, and outliers [12]. In the study area, the significant trend in rainfall and NDVI time series was assessed using the MK significance test at 95\% confidence interval where black area showed a significant trend $\left(H_{1}\right)$ while white area showed no significant trend $\left(H_{0}\right)$.

2.4.2. Residual Trend Analysis (RESTREND) Method. In Gojeb River Catchment, natural and human effects on vegetation degradation were assessed using residual trend analysis (RESTREND) method where negative values indicate degraded area while positive values shown improved vegetation performance. The method is simple and can be used to reveal the spatial heterogeneity of factors driving land degradation at cell resolution [54]. The RESTREND method has been used widely to explore the relationship between climatic and anthropogenic causes of land degradation in various regions of the World [55-57]. The RESTREND method can be used to quantitatively and effectively differentiate climate and human drivers of land degradation $[54,56]$. The residuals can be acquired from the difference between observed NDVI and predicted NDVI and were analyzed to detect the trend over time [58]. If there was a significant decreasing trend of residuals, it would presumably be derived by human activities. Otherwise, if the 
residuals showed no trend over time, the declining vegetation production would be attributed to climate factors such as rainfall [49]. If the residual trend is insignificant, the NDVI variations can be explained with climatic variables; otherwise, NDVI variations might be affected by human activities [1, 31, 59].

2.4.3. Time-Lag Effects of Vegetation (NDVI) Response to Climatic Factor (Rainfall). Since the vegetation is affected by both current and previous rainfall events, the relationship between NDVI and rainfall is characterized by a time-lag response of NDVI in relation to rainfall. Moreover, this relationship can differ significantly depending on the plant growth stage [42]. The rainfall from the CHIRPS is used as the independent variables, whereas the NDVI data from the GIMMS3g, which represents vegetation activities, are used as the dependent variables to evaluate their dependency at different time-lag scales. In this study, the Windowed Cross-Correlation (WCC) method [19] was used, which has been frequently used [60], to analyze the time-lag effects of vegetation greenness response to rainfall. The WCC methods aimed to identify the most significant correlation between NDVI and climatic factor (rainfall), and the corresponding lag time. The models showing the relationships between the NDVI and rainfall were as follows [19]:

$$
\operatorname{NDVI}(i, j)=k_{r f}(i, j) * \operatorname{RF}(i, j)+b_{r f}(i, j),
$$

where $k_{r f}$ refers to the regression coefficient with a time lag of $i$ months; $i$ ranges from 0 to $n$ (i.e., 0 represents no timelag effects, and $1-n$ represents a one- to $n$-month lag, respectively); NDVI refers to the GIMMS3g NDVI time series (1982-2015); and RF is the time series for rainfall with a time lag of $i$. For the climatic factor, the lag month $(i)$ that has the highest determination coefficient $\left(R^{2}\right)$ was the best time lag for the vegetation responses to this climatic factor. Therefore, combined with the rainfall data, correlation coefficients were calculated to compare the monthly lag of NDVI from rainfall. The analysis was based on the pixel scale, where $(i, j)$ refers to the pixel located in the row $i$ and column $j$. The determination coefficient $R^{2}$ of the regression equation was used as an index to evaluate the correlations between NDVI and climatic factors. The highest $R^{2}$ indicated the strongest NDVI response to a climatic factor. The time lag corresponding to the highest $R^{2}$ was regarded as the optimum time lag.

\section{Results and Discussions}

3.1. Annual NDVI and Rainfall Trends in the Gojeb River Catchment, Ethiopia. In the GRC, Sen's slope trend analysis indicated that the magnitude of annual NDVI showed significant decrement especially in the southeast and west of the catchment, while the annual NDVI trend magnitude was significantly increased in the northern and some other portions of the catchment $(P<0.05$; Figure 3$)$. The continent with the highest proportion of significant increasing trends is Europe (49.71\%), followed by South America (40.73\%).
Nevertheless, the majority of the study catchment (around $85 \%$ of the area) did not show significant changes in vegetation dynamics. The continent with the highest proportion of significant decreasing trends of NDVI is North America (7.63\%), followed by South America (7.31\%) [61]. Studies in Asia revealed that vegetation greenness has significantly decreased over the last 33 years [32]. The vegetation trends have shown significant decreasing trends in the southern Amazon forest [62] and in the southern Central African Republic and Uganda [59, 60]. On the other hand, the annual rainfall trend magnitude increased significantly $(P<0.05)$ in the southern part of the catchment. Increasing trends in precipitation are observed in high latitudes in Asia, in middle Europe, and in parts of Africa, while the southwestern United States, northern Mongolia, and northeastern China show decreasing trends [61]. However, the major portion of the study catchment did not show a significant reduction in the annual rainfall trend $(P>0.05$, Figure 3$)$. Similar studies in Northwestern Ethiopia revealed a statistically nonsignificant increasing trend in annual mean rainfall time series during the study period between 1983 and 2014 [34].

In the GRC, the mean annual NDVI and rainfall were found to be $0.72( \pm 0.026)$ and $1652.5 \mathrm{~mm}( \pm 119.99)$, respectively, from 1982 to 2015 . The minimum and maximum annual NDVI values were 0.67 and 0.77 , respectively. The minimum and maximum rainfall varied from 1391 to $1884 \mathrm{~mm}$, respectively. During the study period, between 1982 and 2015, the values of annual NDVI were minimum in 1984, 2000, and 2012, while the maximum values were recorded in 1997 and 2006. Concurrently, the minimum rainfall and maximum rainfall $(\mathrm{mm})$ were observed in 1984, 1999, and 2012, and 1997 and 2006, respectively. The concurrent decrement and increment of annual NDVI and rainfall distributions both spatially and temporarily could be attributed to the significant positive correlation between them $(R=0.637, P \leq 0.001)$. The close resemblance in NDVI and rainfall patterns (in trend and amplitude) in GRC might reveal a close relationship between vegetation and rainfall. Throughout, NDVI shows a clear response to the cycle of rainfall.

\subsection{Monthly NDVI and Rainfall Trends in the Gojeb River} Catchment, Ethiopia. Spatially, the monthly distribution of NDVI was found to be higher in the northern and northwest portion of the catchment, while it is lower in the southern and southeastern portion. Temporally, the monthly minimum and maximum NDVI values were found to be 0.55 and 0.84 , respectively, with an average value of $0.72( \pm 0.06)$. Sen's analysis of trend magnitude showed that the monthly NDVI decreased significantly $(P<0.05$, black area, Figures 4 (a) and $4(b))$ in the southeast (downstream) and northern and other significant portions of GRC. Concurrently, the mean monthly rainfall trend magnitude showed a significant reduction, especially in the southern portion of the catchment (black area, Figures 4(c) and 4(d)) which indicates the strong and positive significant correlation of NDVI and rainfall $(R=0.189, P \leq 0.001)$. 


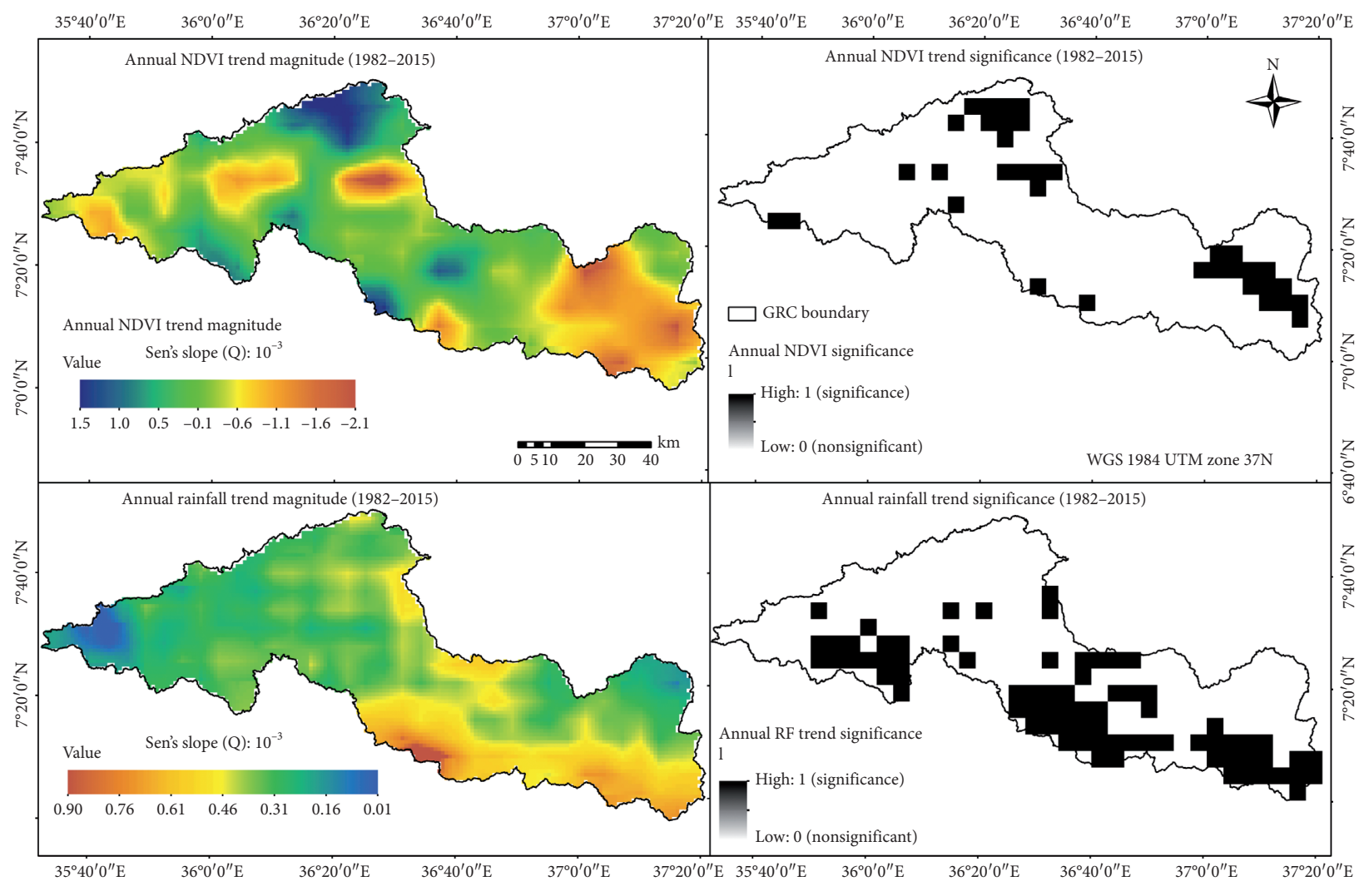

FIgURE 3: Annual NDVI and rainfall trend magnitude (left) and significance (right), GRC.

\subsection{Seasonal NDVI and Rainfall Trends in the Gojeb River} Catchment, Ethiopia. In the GRC, Sen's slope trend magnitude and significance of seasonal NDVI and rainfall trends from 1982 to 2015 are shown in Figures 5 and 6. Accordingly, the lowest and highest seasonal NDVI values were observed during MAM of 1984, 2000, 2012, and 2015 and JJA of $1983,1995,2006$, and 2008, respectively. In the study catchment, the average NDVI values were observed during JJA $>$ SON $>$ DJF $>$ MAM. Similarly, the lowest and highest seasonal rainfall $(\mathrm{mm})$ was observed during DJF of 1984, 1994, 2000, and 2012 and during JJA of 1990 and 2008. The seasonal rainfall distribution also follows the same pattern with NDVI values during the study periods. Generally, the lowest and highest rainfall distribution of GRC is observed during MAM and JJA, respectively. Consequently, the reduction of vegetation cover is observed during DJF and MAM which might be attributed to the significant positive correlation effects of seasonal NDVI and rainfall $(R=0.67, P \leq 0.001)$ during the study periods.

During DJF, Sen's trend analysis and MK significant test indicated that the NDVI trend magnitude increased significantly $(P<0.05)$ in the northern upstream portion of the GRC, while vegetation cover decreased significantly in the downstream portion of GRC. However, the major portions of the study catchment have remained unaltered in vegetation cover during DJF (Figures 5(a) and 5(e)). Concurrently, though not statistically significant, the rainfall trend magnitude has shown decrement in almost all portions, particularly in the downstream portion, of the study catchment during DJF of the study period (Figures 6(a) and $6(\mathrm{e}))$. However, it remained unaltered in the western part of the upstream part of the catchment.

During MAM, Sen's trend analysis showed that the NDVI trend magnitude decreased in most portions of the study catchment, particularly in the downstream and west of the upstream portions (Figure 5(a)). However, MK significant test indicated that the NDVI trend decreased significantly in the downstream portion of the GRC $(P<0.05$, Figure 5(e)). During JJA, Sen's trend analysis and MK significant test showed that the NDVI trend magnitude increased significantly in the mid and northern upstream portions of the study catchment (Figures 5(c) and $5(\mathrm{~g}))$.

On the other hand, during MAM, Sen's trend analysis and MK significant test showed that the rainfall trend magnitude did not increase significantly throughout the GRC $(P>0.05$, Figures 6(b) and 6(f)). Concurrently, the rainfall trend magnitude did not show any significant changes across the catchment, except in some downstream portions of GRC (Figures 6(c) and 6(g)). During SON, the NDVI trend magnitude showed a significant reduction in some parts of the catchment, while some other portions of the catchment also showed some increment in vegetation cover not statistically significant (Figures 5(d) and 5(h)). Simultaneously, Sen's trend magnitude of rainfall did not show significant increment, except for some small portions of the catchment which showed a significant increase in rainfall trend magnitude (Figures 6(d) and 6(h)). 


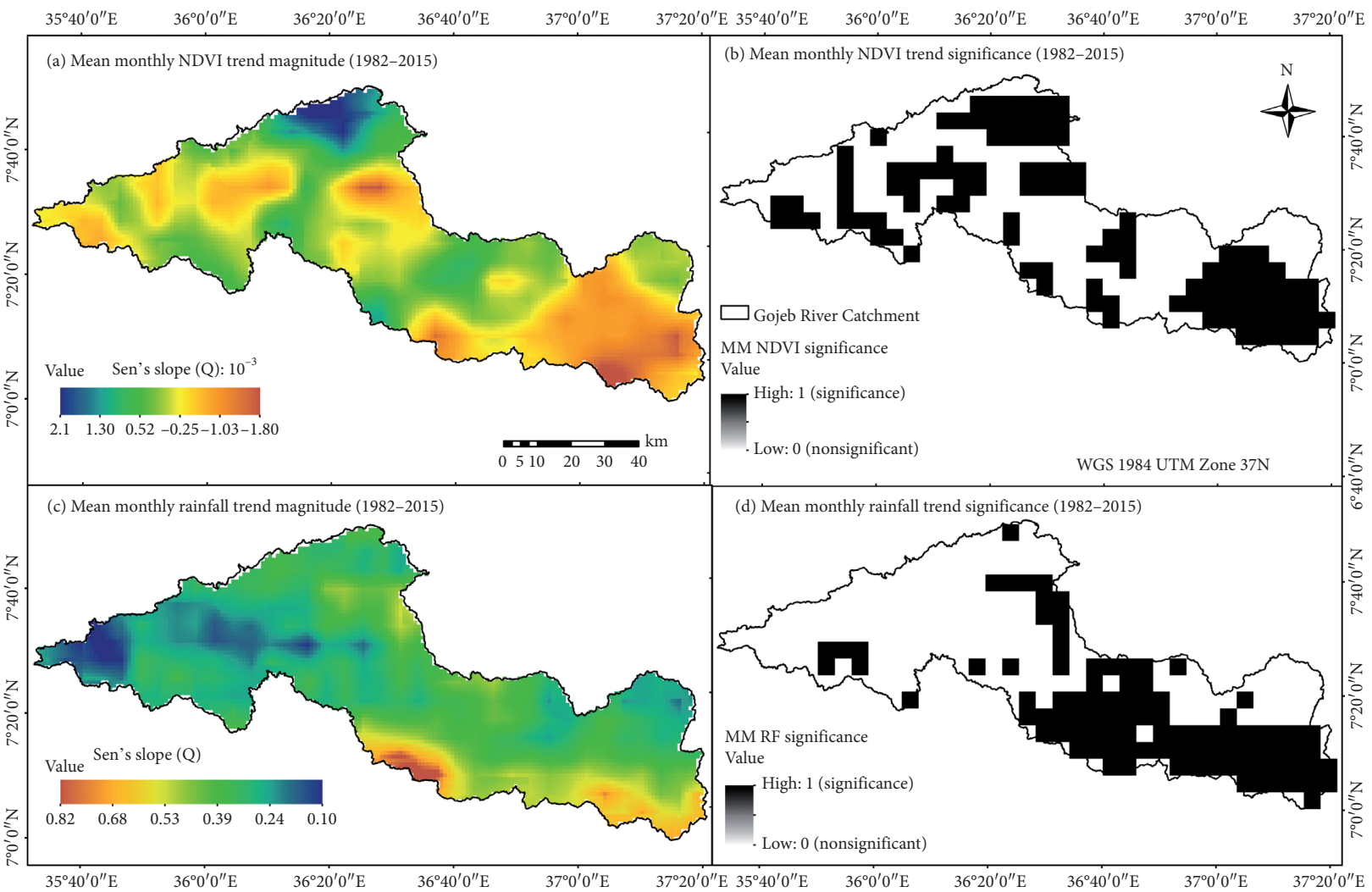

FIGURE 4: Mean monthly NDVI and rainfall trend magnitude (Sen's slope_Q) and significance from 1982 to 2015 in the GRC.

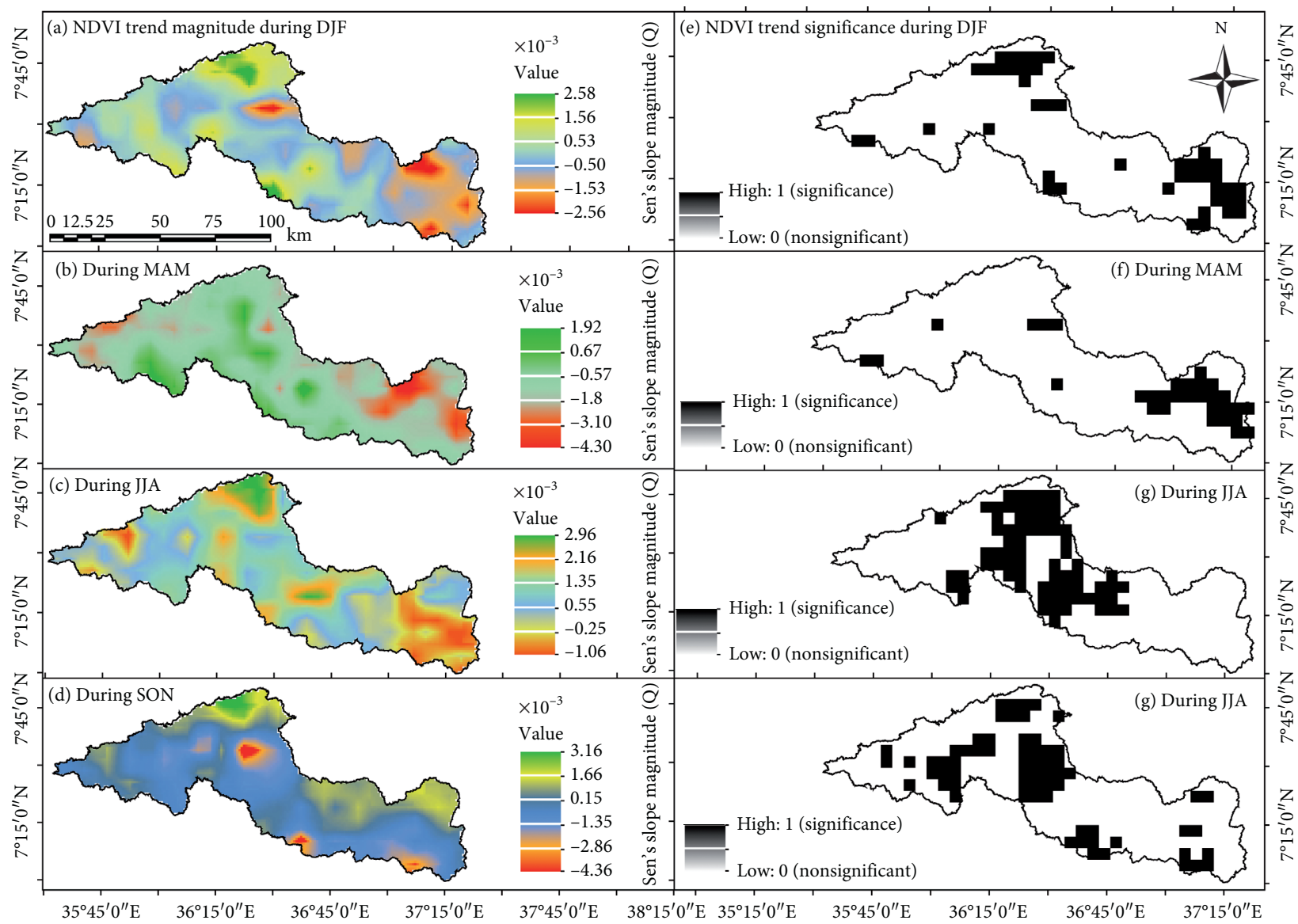

FIGURE 5: Seasonal NDVI trend magnitude and significance during DJF, MAM, JJA, and SON between 1982 and 2015 in GRC. 


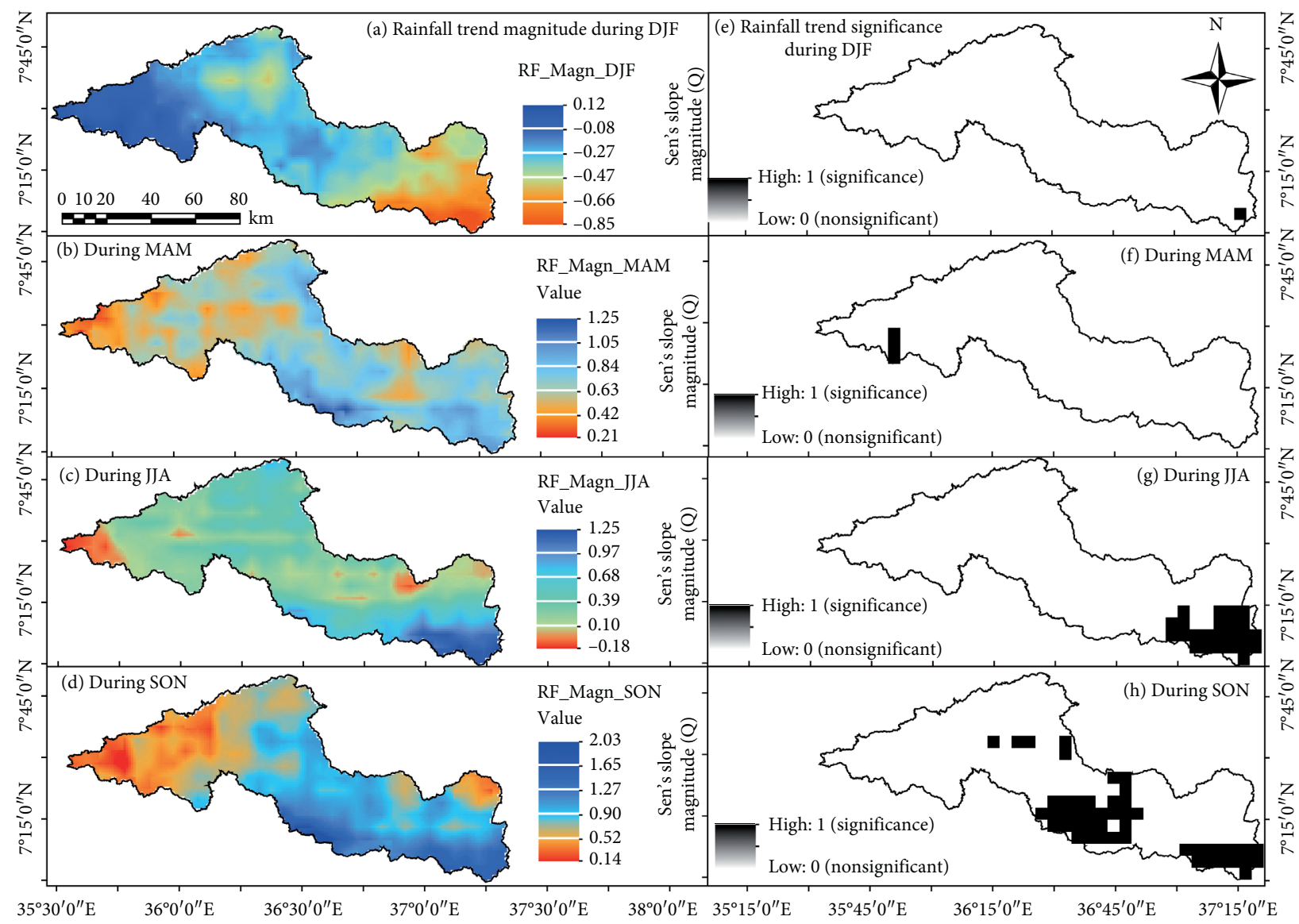

FIGURE 6: Seasonal rainfall trend magnitude and significance during DJF, MAM, JJA, and SON in GRC.

3.4. NDVI RESTREND in the Gojeb River Catchment, Ethiopia. In principle, RESTREND can identify the pixels that have experienced a reduction or an increase in biomass production per unit rainfall over a period of time [57]. It provides an effective tool to distinguish between the effects of climatic factors and human activities on vegetation changes when used properly where negative values indicate degraded area while positive values shown improved vegetation performance [56]. If there was a significant decrease and no trend of residuals (difference of observed and predicted NDVI [58] over time), the vegetation degradation would be derived by human activities and climate factors such as rainfall [49], respectively. If the residual trend is insignificant, the NDVI variations can be explained with climatic variables $[1,31,59]$. The NDVI linear slopes (Figure 7) examine the spatial patterns of the rate of NDVI changes and the minimum value of NDVI and how they relate to changes in rainfall from 1982 to 2015. In the GRC, the negative values (Figure 7) indicated the vegetation degradation, while the positive values showed improved vegetation performance. And, the zero values of NDVI linear slope indicated the unaltered vegetation cover in the study catchment.

In the GRC, a strongly negative decrease of NDVI, for instance, during 1984, 2000, 2008, and 2005 (Figure 8), could be derived by human-induced vegetation degradation. On the contrary, the strong positive increase of NDVI, during 1997 and 2007, could be attributed to the rainfall variability in the study catchment. The RESTREND analysis showed that the NDVI trend magnitude residuals decreased significantly in the downstream portion of the GRC (Figure 9) which might be derived by human activities. The trend magnitude residuals also showed a significant increment in the northern portion of the upper catchment which could, in turn, be attributed to the variability of rainfall. In the study catchment, there are also places in which the residuals showed no trends over time which could be affected by climatic (rainfall) variability (Figure 9). Similarly, studies, elsewhere, [56] reported that NDVI increases in response to higher rainfall in the areas with positive slopes.

The RESTREND method assumes that areas that show a negative trend are degraded, while those with a positive trend are improved or at least not degraded. Figure 9 shows areas with positive and negative trends of vegetation productivity that have been derived by either human activities or rainfall. The RESTREND residual trend magnitude based on rainfall shows both areas with positive and negative trends (Figure 9). The RESTREND maps show areas that are likely subject to land degradation (negative trend of residuals) or not (positive residuals) (Figure 9). The dominance of a decreasing trend in the residuals at the pixel level for the 


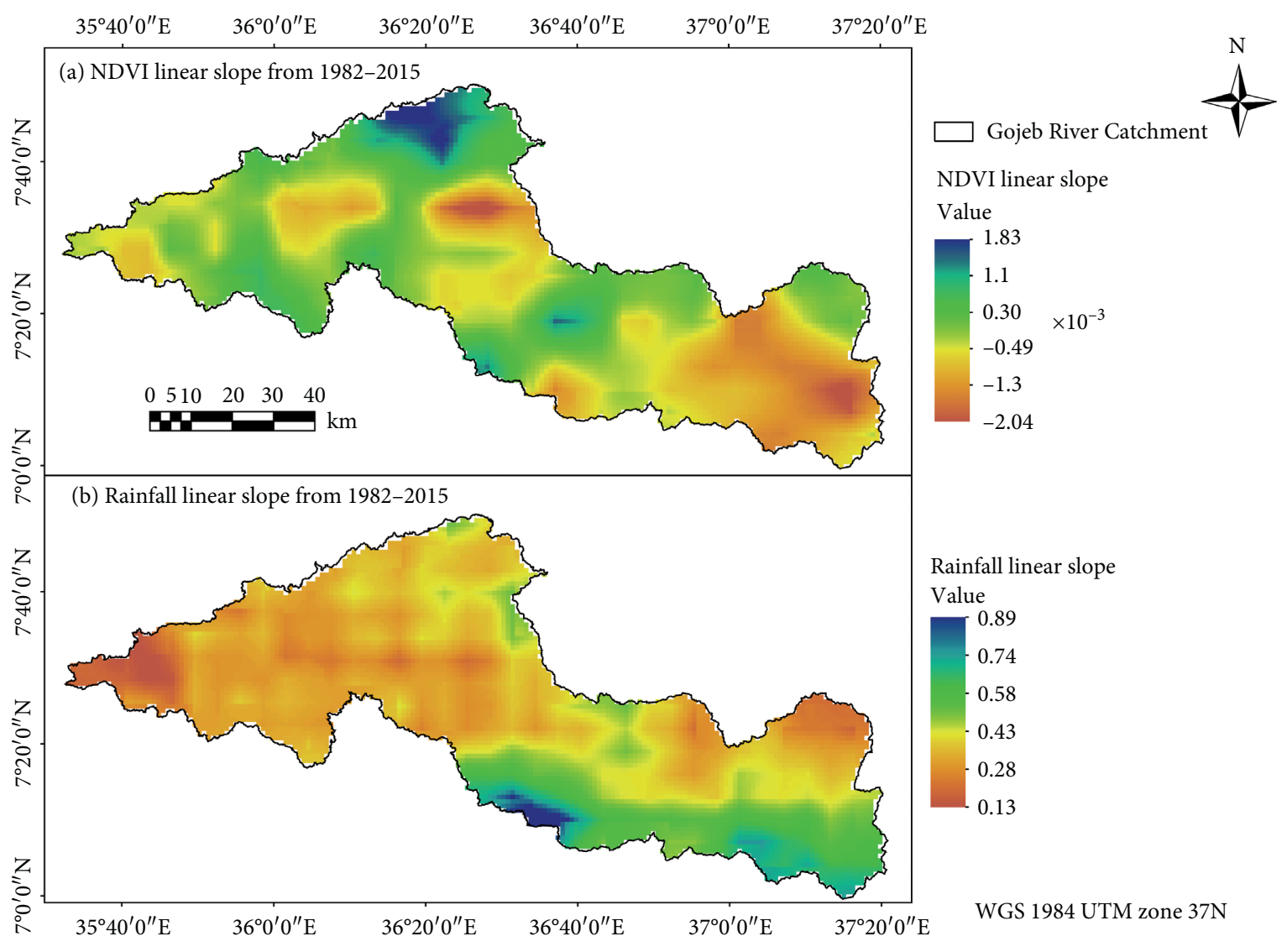

FIgURE 7: NDVI and rainfall linear slope between 1982 and 2015 in Gojeb River Catchment.

NDVI from 1982, 1984, 2000, 2008 to 2012 indicates vegetation degradation, whereas a strong upward trend in the residuals was evident from 1983, 1991, 1998 to 2007, indicative of vegetation improvements. The significant relationship between vegetation production and rainfall was the basic premise of the RESTREND method [49]. Evans and Geerken [63] first proposed the NDVI-based RESTREND method to distinguish between vegetation degradation due to climatic variations and that caused by human activities in Syria. If the significant climate effects could be removed from the long-term trends of NDVI, human-induced land degradation might be distinguished [58]. He et al. [54] differentiated human-induced drivers from climatic drivers of grassland degradation in the Liao River Basin using the RESTREND method. Studies [54] showed that the RESTREND method is an effective and reliable tool to help identify the driving factors of vegetation degradation. Accordingly, they reported that climate variability and human activities contributed equally to the vegetation degradation in the Otindag Sandy Land. Rainfall is a major driving force and the most important factor in promoting vegetation growth and natural grasslands and forests of the world [64]. In the study catchment, the residuals may result from a number of factors, including climatic variations (mainly rainfall), natural disturbances (e.g., flooding), and human activities (livestock grazing, population, rural settlement, agriculture, fuel wood and charcoal extraction, and timber production).
3.5. NDVI-Rainfall Correlation Analysis in the Gojeb River Catchment, Ethiopia. In the GRC, Pearson's correlation was utilized to analyze the relationship between overall vegetation dynamics (NDVI) and climatic variations (rainfall) over the period 1982-2015 (Table 1). The annual NDVI had a significant positive correlation with rainfall $\left(\mathrm{R}_{\mathrm{NDVI}}\right.$ $\mathrm{RF}=0.637, P \leq 0.001)$. Similarly, the monthly NDVI had a significant positive correlation with rainfall $\left(\mathrm{R}_{\mathrm{NDVI}}\right.$ $\mathrm{RF}=0.189, P \leq 0.001)$. In consistent with this finding, Qiu et al. [65] observed significantly positive NDVI-climate relationship on the denoised time series in most vegetated regions. However, the seasonal NDVI did not show any significant $(P>0.05)$ correlation with rainfall. On the contrary, Chu et al. [1] reported that the NDVI had a quite significant seasonal correlation with precipitation.

The annual and monthly spatial distributions of NDVI and rainfall correlation analysis have been shown in Figure 10. In the GRC, spatially, positive correlations between annual NDVI and rainfall in almost all portions were obtained, while very small portions of the western part of the catchment showed negative correlations between them during the study periods (Figure 10(a)). The negative NDVI-rainfall correlation coefficients could be mainly associated with the negative dynamic trends of either NDVI or climatic factors [65]. In line with our findings, the spatial relationship between NDVI and precipitation was quite different among vegetation types and seasons [1]. In Gojam of Ethiopia, Getahun and Shefine [20] reported a strong 


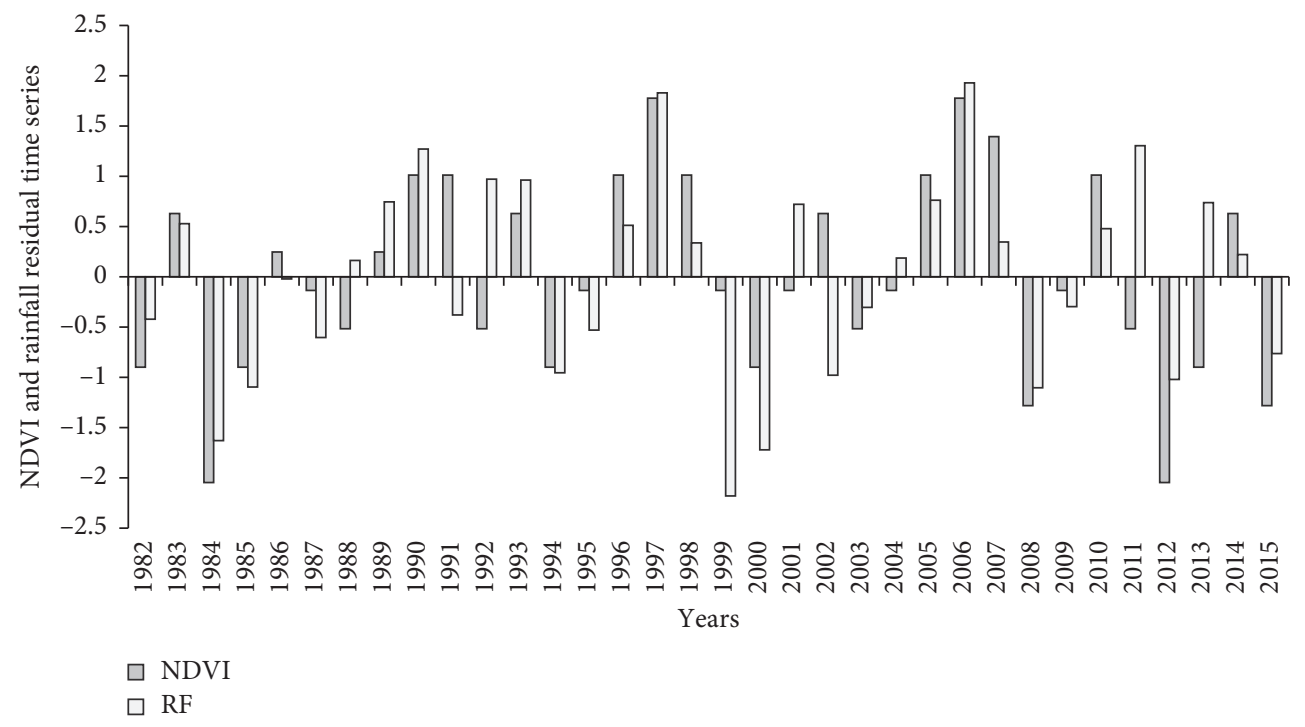

FIgURE 8: Annual NDVI and rainfall residual time series from 1982 to 2015 in the GRC.

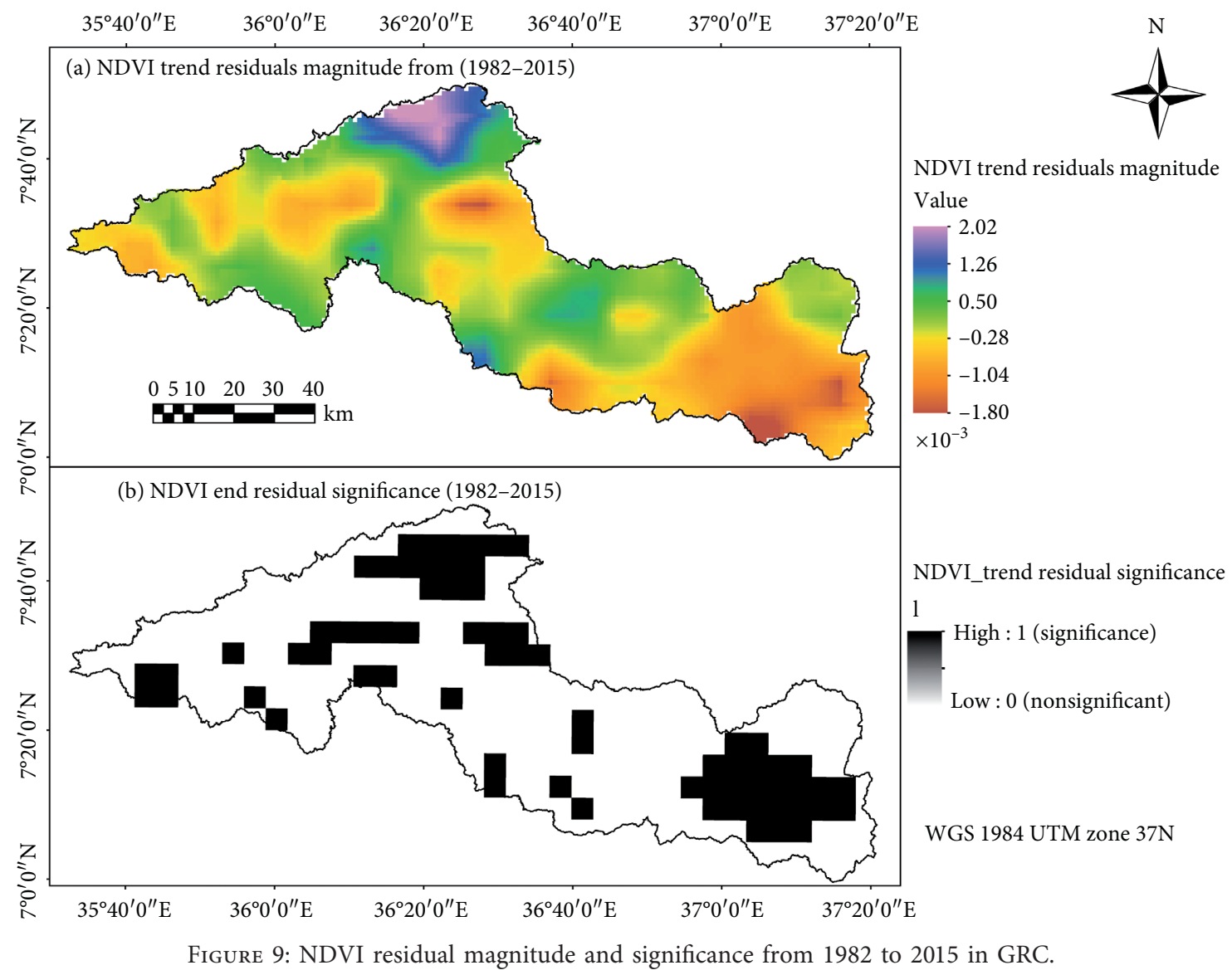

positive linear correlation between NDVI and rainfall. They also confirmed very high annual correlation coefficients between NDVI and precipitation. Similarly, Bao et al. [5] reported the strong positive correlation between NDVI and precipitation in most areas of Mongolian plateau for the periods between 1982 and 2010 suggesting that precipitation is the most direct influencing factor on vegetation dynamics. On the contrary, in Northwestern Ethiopia, the parallel assessment of the NDVI and precipitation time series showed the lower dependency of vegetation change on the long-term precipitation changes [34]. Moreover, the major portions of the catchment showed positive correlation 
TABLE 1: The annual, monthly, and seasonal (DJF, MAM, JJA, and SON) correlation of NDVI with rainfall ( $\left.\mathrm{R}_{\mathrm{NDVI}-\mathrm{RF}}\right)$ in Gojeb River Catchment over the period 1982-2015.

\begin{tabular}{lccccrr}
\hline Periods & Annual & Monthly & DJF & MAM & JJA & SON \\
\hline $\mathrm{R}_{\mathrm{NDVI}-\mathrm{RF}}$ & $0.637^{* *}$ & $0.189^{* *}$ & 0.296 & -0.039 & 0.051 & 0.145 \\
$P$ value & 0.000 & 0.000 & 0.089 & 0.828 & 0.773 & 0.412 \\
\hline
\end{tabular}

${ }^{* *}$ Correlation is significant at the 0.01 level. (2-tailed).

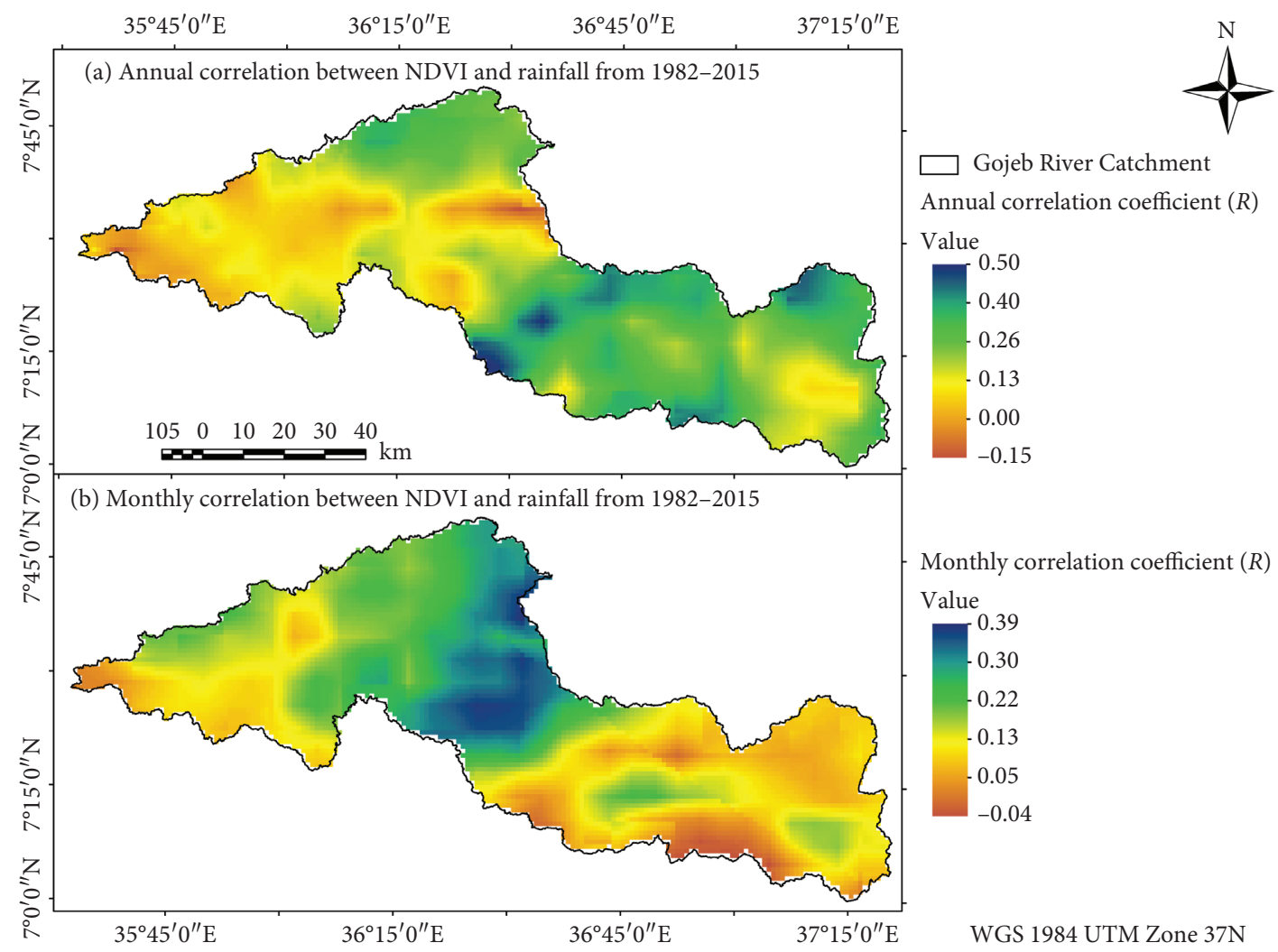

Figure 10: Annual and monthly NDVI and rainfall correlation coefficient from 1982 to 2015 in GRC.

though there have been some portions in which negative correlations were obtained between the monthly NDVI and rainfall relationships (Figure 10(b)). Regarding the seasonal NDVI and rainfall correlation, there were relatively higher strong positive correlations during December, January, and February, DJF, though other seasons also showed positive correlations. On the contrary, there were also portions of the catchment which showed negative correlations during all seasons which might be associated with the quality of GIMMS datasets and with their negative dynamic trends. The vegetation growth has the strongest correlation with the precipitation of last month in most of Africa (excluding central Africa) [61].

\subsection{Lag Time Effects of NDVI Responses to Rainfall in the Gojeb} River Catchment, Ethiopia. An image showing the spatial distribution of time lag between NDVI and rainfall was provided in Figure 11. The time lag between NDVI and climate factors (rainfall) varied with different climatic regions and vegetation cover of the study catchment. Regarding the time lag between NDVI and rainfall, the majority of the pixels ( $>85 \%$ ) were examined with 1.6-3.3 months' time lag. Other areas were observed with a time lag of less than 1.6 and a very small portion of the catchment with 3.3 to 4 months. In the study catchment, the minimum and maximum NDVI values were observed during March (0.66) and September (0.78) while the minimum rainfall and maximum rainfall have been observed during December $(41 \mathrm{~mm})$ and January $(41 \mathrm{~mm})$ and July $(233 \mathrm{~mm})$, respectively, which indicated that the NDVI is getting maximum three months after the rainfall is maximal. Therefore, in the GRC, the majority of time lags are two to three months. In consistent with this finding, other authors $[66,67]$ revealed the dependence of vegetation growth on the climatic factors (rainfall) having a certain time lag effect which varies from 0 to 3 months. The growth of vegetation response to precipitation has been documented in the northern hemisphere (no profound time lag in most places), Southeast China, central and eastern North America (a time lag of 1-2 


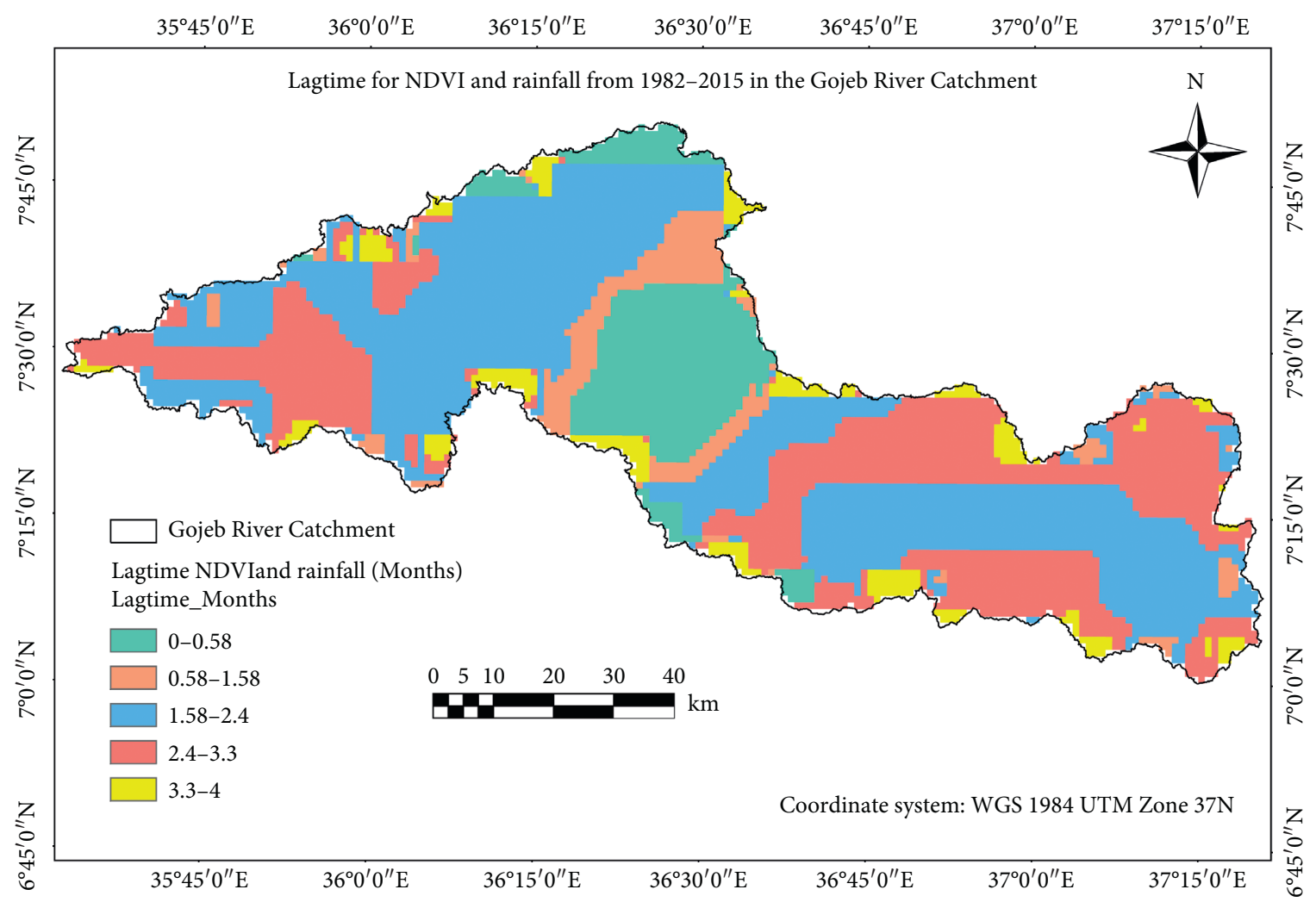

FIgURe 11: Spatial distribution of lag time for NDVI and rainfall from 1982 to 2015 in the Gojeb River Catchment.

months), southern South America (time lag of 1 month), and Australia (1- to 2-month time lag to precipitation) [60,61].

\section{Conclusion}

This study analyzed the spatial and temporal NDVI variations in the annual, monthly, and four different seasons (DJF, MAM, JJA, and SON) in the Gojeb River Catchment and their response to climatic factors (rainfall) from 1982 to 2015 based on GIMMS datasets and CHIRPS time series. The NDVI-rainfall relationship evolves both temporally and spatially. In the GRC, Sen's slope trend analysis indicated that the magnitude of annual NDVI showed significant decrement especially in the southeast and west of the catchment and significantly increased in the northern and some other portions of the catchment. The annual rainfall trend magnitude increased significantly $(P<0.05)$ in the southern part of the catchment. Nevertheless, the majority of the study catchment (around $85 \%$ of the area) did not show significant changes in vegetation dynamics and a significant reduction of annual rainfall trends. In the GRC, concurrent decrement and increment of annual NDVI and rainfall distributions both spatially and temporarily were observed. The close resemblance in NDVI and rainfall patterns (in trend and amplitude) in GRC might reveal a close relationship between them. Sen's analysis of trend magnitude showed that the mean monthly NDVI and rainfall decreased significantly in the southeast (downstream) and northern and other significant portions of GRC which indicate the strong and positive significant correlation of NDVI and rainfall $(R=0.189, P \leq 0.001)$. In the GRC, the lowest and highest seasonal NDVI values and rainfall distributions were observed during MAM and JJA, respectively, indicating similar patterns of seasonal rainfall distribution with NDVI values during the study periods. Consequently, the reduction of vegetation cover is observed during DJF and MAM which might be attributed to the significant positive correlation of seasonal NDVI and rainfall during the study periods.

In the GRC, the RESTREND analysis showed that a strongly negative decrease of NDVI, for instance, during $1984,2000,2008$, and 2005 , could be derived by humaninduced vegetation degradation. On the contrary, the strong positive increase of NDVI, during 1997 and 2007, could be attributed to the rainfall variability in the study catchment. The RESTREND analysis showed that the NDVI trend magnitude residuals decreased significantly in the downstream portion of the GRC which might be derived by human activities. The trend magnitude residuals also showed a significant increment in the northern portion of the upper catchment which could, in turn, be attributed to the variability of rainfall. In the study catchment, there are also places in which the residuals showed no trends over time which could be affected by climatic (rainfall) variability. The dominance of a decreasing trend in the residuals at the pixel level for the NDVI from 1982, 1984, 2000, 2008 to 2012 indicates vegetation degradation, whereas a strong upward trend in the residuals was evident from 1983, 1991, 1998 to 2007, indicative of vegetation improvements. 
In the GRC, unlike the seasonal, Pearson's correlation analysis revealed a significant positive correlation of the monthly $\left(\mathrm{R}_{\mathrm{NDVI}-\mathrm{RF}}=0.189, P \leq 0.001\right)$ and annual $\left(\mathrm{R}_{\mathrm{NDVI}}\right.$ $\mathrm{RF}=0.637, P \leq 0.001) \mathrm{NDVI}$ with rainfall. In the study catchment, spatially, positive correlations between annual NDVI and rainfall in almost all portions of the catchment were obtained during the study periods. Regarding the seasonal NDVI and rainfall correlation, there were relatively higher strong positive correlations during December, January, and February, DJF, though other seasons also showed positive correlations.

The time lag between NDVI and climate factors (rainfall) varied with different climatic regions and vegetation cover of the study catchment. Regarding the time lag between NDVI and rainfall, the majority of the pixels (>85\%) were examined with 1.6-3.3 months' time lag. Other areas were observed with a time lag of less than 1.6 and a very small portion of the catchment with 3.3 to 4 months. In the study catchment, the minimum and maximum NDVI values were observed during March (0.66) and September (0.78) while the minimum rainfall and maximum rainfall have been observed during December $(41 \mathrm{~mm})$ and January $(41 \mathrm{~mm})$ and July $(233 \mathrm{~mm})$, respectively, which indicated that the NDVI is getting maximum three months after the rainfall is maximal. In the study catchment, the majority time lags are two to three months.

\section{Data Availability}

The data used to support the findings of this study are available from the corresponding author upon request.

\section{Conflicts of Interest}

The authors declare that they have no conflicts of interest.

\section{Acknowledgments}

The authors are very grateful to thank the Italian contribution to the Education Sector Development Program (ESDP) under Haramaya University research grant, Ethiopia, for financial support to the study.

\section{References}

[1] H. Chu, S. Venevsky, C. Wu, and M. Wang, "NDVI-based vegetation dynamics and its response to climate changes at Amur-Heilongjiang River Basin from 1982 to 2015," Science of the Total Environment, vol. 650, pp. 2051-2062, 2019.

[2] M. A. Zoran, L. F. V. Zoran, and A. I. Dida, "Forest vegetation dynamics and its response to climate changes," in Proceedings of the SPIE 9998, Remote Sensing for Agriculture, Ecosystems, and Hydrology XVIII, Edinburgh, UK, October 2016.

[3] J. T. Al-Bakri and A. S. Suleiman, "NDVI response to rainfall in different ecological zones in Jordan," International Journal of Remote Sensing, vol. 25, no. 19, pp. 3897-3912, 2004.

[4] S. Vicente-Serrano, D. Cabello, M. Tomás-Burguera et al., "Drought variability and land degradation in semiarid regions: assessment using remote sensing data and drought indices (1982-2011)," Remote Sensing, vol. 7, no. 4, pp. 4391-4423, 2015.
[5] G. Bao, Z. Qin, Y. Bao, Y. Zhou, W. Li, and A. Sanjjav, "NDVIbased long-term vegetation dynamics and its response to climatic change in the Mongolian plateau," Remote Sensing, vol. 4, no. 6, pp. 8337-8358, 2014.

[6] D. Mao, Z. Wang, L. Luo, and C. Ren, "Integrating AVHRR and MODIS data to monitor NDVI changes and their relationships with climatic parameters in northeast China," International Journal of Applied Earth Observation and Geoinformation, vol. 18, pp. 528-536, 2012.

[7] W. Kalisa, T. Igbawua, M. Henchiri et al., "Assessment of climate impact on vegetation dynamics over East Africa from 1982 to 2015," Scientific Reports, vol. 9, no. 1, 2019.

[8] J. V. Revadekar, Y. K. Tiwari, and K. R. Kumar, "Impact of climate variability on NDVI over the Indian region during 1981-2010," International Journal of Remote Sensing, vol. 33, no. 22, pp. 7132-7150, 2012.

[9] T. M. Lillesand and R. W. Kiefer, Remote Sensing and Image Interpretation, John Wiley, and Sons, Inc., London, UK, 4th edition, 2005.

[10] A. Anyamba and C. J. Tucker, "Analysis of Sahelian vegetation dynamics using NOAA-AVHRR NDVI data from 1981-2003," Journal of Arid Environments, vol. 63, no. 3, pp. 596-614, 2005.

[11] I. Fabricante, M. Oesterheld, and J. M. Paruelo, "Annual and seasonal variation of NDVI explained by current and previous precipitation across Northern Patagonia," Journal of Arid Environments, vol. 73, no. 8, pp. 745-753, 2009.

[12] T. Udelhoven, M. Stellmes, G. del Barrio, and J. Hill, "Assessment of rainfall and NDVI anomalies in Spain (1989-1999) using distributed lag models," International Journal of Remote Sensing, vol. 30, no. 8, pp. 1961-1976, 2009.

[13] T. Wang, X. Kou, Y. Xiong, P. Mou, J. Wu, and J. Ge, "Temporal and spatial patterns of NDVI and their relationship to precipitation in the Loess Plateau of China," International Journal of Remote Sensing, vol. 31, no. 7, pp. 1943-1958, 2010.

[14] S. C. Jammes and H. Fritz, "Precipitation-NDVI relationships in eastern and southern African savannas vary along a precipitation gradient," International Journal of Remote Sensing, vol. 30, no. 13, pp. 7132-7150, 2009.

[15] N. Martiny, P. Camberlin, Y. Richard, and N. Philippon, "Compared regimes of NDVI and rainfall in semi-arid regions of Africa," International Journal of Remote Sensing, vol. 27, no. 23, pp. 5201-5223, 2006.

[16] S. Huber, R. Fensholt, and K. Rasmussen, "Water availability as the driver of vegetation dynamics in the African Sahel from 1982 to 2007," Global and Planetary Change, vol. 76, no. 3-4, pp. 186-195, 2011.

[17] S. Georganos, A. M. Abdi, D. E. Tenenbaum, and S. Kalogirou, "Examining the NDVI-rainfall relationship in the semi-arid Sahel using geographically weighted regression," Journal of Arid Environments, vol. 146, pp. 64-74, 2017.

[18] S. C. Jammes, H. Fritz, and F. Murindagomo, "Spatial patterns of the NDVI-rainfall relationship at the seasonal and interannual time scales in an African savanna," International Journal of Remote Sensing, vol. 27, no. 23, pp. 5185-5200, 2006.

[19] W. Zhao, X. Zhao, T. Zhou, D. Wu, B. Tang, and H. Wei, "Climatic factors driving vegetation declines in the 2005 and 2010 Amazon droughts," PLoS One, vol. 12, no. 4, Article ID e0175379, 2017.

[20] Y. S. Getahun and B. G. Shefine, "Analysis of climate variability (ENSO) and vegetation dynamics in gojjam, Ethiopia," J Journal of Earth Science and Climatic Change, vol. 6, p. 320, 2015. 
[21] T. Ning, W. Liu, W. Lin, and X. Song, "NDVI variation and its responses to climate change on the northern loess plateau of China from 1998 to 2012," Advances in Meteorology, vol. 2015, Article ID 725427, 2015.

[22] V. Nischitha, S. A. Ahmed, H. Varikoden, and J. V. Revadekar, "The impact of seasonal rainfall variability on NDVI in the Tunga and Bhadra river basins, Karnataka, India," International Journal of Remote Sensing, vol. 35, no. 23, pp. 80258043, 2014.

[23] C. Huang, Y. Li, G. Liu, H. Zhang, and Q. Liu, "Recent climate variability and its impact on precipitation, temperature, and vegetation dynamics in the Lancang River headwater area of China," International Journal of Remote Sensing, vol. 35, no. 8, pp. 2822-2834, 2014.

[24] C. J. Tucker, J. E. Pinzon, M. E. Brown et al., “An extended AVHRR 8-km NDVI dataset compatible with MODIS and SPOT vegetation NDVI data," International Journal of Remote Sensing, vol. 26, no. 20, pp. 4485-4498, 2005.

[25] K. Wolka, G. Sterk, B. Biazin, and M. Negash, "Benefits, limitations and sustainability of soil and water conservation structures in Omo-Gibe basin, Southwest Ethiopia," Land Use Policy, vol. 73, pp. 1-10, 2018.

[26] G. Kochito, "Impact assessment of climate change on the hydrology of Gojeb River catchment in western Omo-Gibe River basin, Ethiopia," MSc Thesis, School of Graduate Studies, Haramaya University, Ethiopia, 2014.

[27] M. A. Denboba, "Forest coversion-soil degradation-farmers perception nexus: implications for sustainable land use in the southwest of Ethiopia," in Center for Development Research, Ecology and Development Series No. 26, P. L. G. Velk, M. Denich, C. Martius et al., Eds., pp. 1-149, University of Bonn, Bonn, Germany, https://tinyurl.com/yygkhbnh.

[28] CSA (Central Statistical Authority), The Population and Housing Census of Ethiopia: Results at a Country Level, Central Statistical Authority (CSA), Addis Ababa, Ethiopia, 2007.

[29] F. Detsch, I. Otte, T. Appelhans, A. Hemp, and T. Nauss, "Seasonal and long-term vegetation dynamics from $1-\mathrm{km}$ GIMMS-based NDVI time series at Mt. Kilimanjaro, Tanzania," Remote Sensing of Environment, vol. 178, pp. 70-83, 2016.

[30] R. Fensholt and S. R. Proud, "Evaluation of Earth observation based global long term vegetation trends-comparing GIMMS and MODIS global NDVI time series," Remote Sensing of Environment, vol. 119, pp. 131-147, 2012.

[31] L. Jiang, J. Guli.Jiapaer, A. Bao, H. Guo, and F. Ndayisaba, "Vegetation dynamics and responses to climate change and human activities in Central Asia," Science of the Total Environment, vol. 599-600, pp. 967-980, 2017.

[32] M. Lamchin, W.-K. Lee, S. W. Jeon et al., "Long-term trend and correlation between vegetation greenness and climate variables in Asia based on satellite data," Science of the Total Environment, vol. 618, pp. 1089-1095, 2018.

[33] T. Landmann and O. Dubovyk, "Spatial analysis of humaninduced vegetation productivity decline over eastern Africa using a decade (2001-2011) of medium resolution MODIS time-series data," International Journal of Applied Earth Observation and Geoinformation, vol. 33, pp. 76-82, 2014.

[34] W. Zewdie, E. Csaplovics, and L. Inostroza, "Monitoring ecosystem dynamics in northwestern Ethiopia using NDVI and climate variables to assess long term trends in dryland vegetation variability," Applied Geography, vol. 79, pp. 167178, 2017.
[35] C. J. Tucker, "Red and photographic infrared linear combinations for monitoring vegetation," Remote Sensing of Environment, vol. 8, no. 2, pp. 127-150, 1979.

[36] Y. Bai, Y. Yang, and H. Jiang, "Intercomparison of AVHRR GIMMS3g, terra MODIS, and SPOT-VGT NDVI products over the Mongolian plateau," Remote Sensing, vol. 11, no. 17, p. 2030, 2019.

[37] X. Zhou, Y. Yamaguchi, and S. Arjasakusuma, "Distinguishing the vegetation dynamics induced by anthropogenic factors using vegetation optical depth and AVHRR NDVI: a cross-border study on the Mongolian Plateau," Science of the Total Environment, vol. 616-617, pp. 730-743, 2018.

[38] J. Q. Du, J. M. Shu, Y. H. Wang, Y. C. Li, and G. Yang, "Comparison of GIMMS and MODIS normalized vegetation index composite data for Qinghai-Tibet Plateau," Chinese Journal of Applied Ecology, vol. 25, p. 533, 2014.

[39] Y. Ibrahim, H. Balzter, J. Kaduk, and C. Tucker, "Land degradation assessment using residual trend analysis of GIMMS NDVI3g, soil moisture and rainfall in sub-saharan west africa from 1982 to 2012," Remote Sensing, vol. 7, no. 5, pp. 5471-5494, 2015.

[40] F.-W. Zeng, G. Collatz, J. Pinzon, and A. Ivanoff, "Evaluating and quantifying the climate-driven interannual variability in global inventory modeling and mapping studies (GIMMS) normalized difference vegetation index (NDVI3g) at global scales," Remote Sensing, vol. 5, no. 8, pp. 3918-3950, 2013.

[41] J. Pinzón, M. E. Brown, and C. J. Tucker, "Empirical Mode Decomposition (EMD) correction of orbital drift artefacts in satellite data stream," in The Hilbert-Huang Transform and its Applications, N. Huang and S. Shen, Eds., World Scientific Publishing, Singapore, pp. 167-183, 2005.

[42] Y. Zhou, L. Zhang, R. Fensholt, K. Wang, I. Vitkovskaya, and F. Tian, "Climate contributions to vegetation variations in central Asian drylands: pre- and post-USSR collapse," Remote Sensing, vol. 7, no. 3, pp. 2449-2470, 2015.

[43] H. Li, Y. Li, Y. Gao, C. Zou, S. Yan, and J. Gao, "Human impact on vegetation dynamics around Lhasa, Southern Tibetan Plateau, China," Sustainability, vol. 8, no. 11, p. 1146, 2016.

[44] J. Li, K. Fan, and L. M. Zhou, "Satellite observations of El Nino impacts on Eurasian spring vegetation greenness during the period 1982-2015," Remote Sensing, vol. 9, no. 7, p. 628, 2017.

[45] B. N. Holben, "Characteristics of maximum-value composite images from temporal AVHRR data," International Journal of Remote Sensing, vol. 7, no. 11, pp. 1417-1434, 1986.

[46] R. Fensholt, K. Rasmussen, P. Kaspersen, S. Huber, S. Horion, and E. Swinnen, "Assessing land degradation/recovery in the African Sahel from long-term Earth observation based primary productivity and precipitation relationships," Remote Sensing, vol. 5, no. 2, pp. 664-686, 2013.

[47] C. Funk, P. Peterson, M. Landsfeld et al., "The climate hazards infrared precipitation with stations-a new environmental record for monitoring extremes," Scientific Data, vol. 2, no. 1, p. 150066, 2015.

[48] R. D. Koster, S. P. P. Mahanama, B. Livneh, D. P. Lettenmaier, and R. H. Reichle, "Skill in streamflow forecasts derived from large-scale estimates of soil moisture and snow," Nature Geoscience, vol. 3, no. 9, pp. 613-616, 2010.

[49] S. Huang and J. Kong, "Assessing land degradation dynamics and distinguishing human-induced changes from climate factors in the three-north shelter forest region of China," ISPRS International Journal of Geo-Information, vol. 5, no. 9, p. 158, 2016. 
[50] B. Önöz and M. Bayazit, "Block bootstrap for Mann-Kendall trend test of serially dependent data," Hydrological Processes, vol. 26, no. 23, pp. 3552-3560, 2012.

[51] F. Fathian, Z. Dehghan, M. H. Bazrkar, and S. Eslamian, "Trends in hydrologic and climatic variables affected by four variations of Mann-Kendall approach in Urmia Lake basin, Iran," Hydrological Sciences Journal, 2014.

[52] R. Modarres and V. de Paulo Rodrigues da Silva, "Rainfall trends in arid and semi-arid regions of Iran," Journal of Arid Environments, vol. 70, no. 2, pp. 344-355, 2007.

[53] R. de Jong, S. de Bruin, A. de Wit, M. E. Schaepman, and D. L. Dent, "Analysis of monotonic greening and browning trends from global NDVI time-series," Remote Sensing of Environment, vol. 115, no. 2, pp. 692-702, 2011.

[54] C. He, J. Tian, B. Gao, and Y. Zhao, "Differentiating climateand human-induced drivers of grassland degradation in the Liao River Basin, China," Environmental Monitoring and Assessment, vol. 187, no. 1, p. 4199, 2014.

[55] S. M. Herrmann, A. Anyamba, and C. J. Tucker, "Recent trends in vegetation dynamics in the African Sahel and their relationship to climate," Global Environmental Change, vol. 15, no. 4, pp. 394-404, 2005.

[56] A. Li, J. Wu, and J. Huang, "Distinguishing between humaninduced and climate-driven vegetation changes: a critical application of RESTREND in Inner Mongolia," Landscape Ecology, vol. 27, no. 7, pp. 969-982, 2012.

[57] K. J. Wessels, S. D. Prince, J. Malherbe, J. Small, P. E. Frost, and D. VanZyl, "Can human-induced land degradation be distinguished from the effects of rainfall variability? a case study in South Africa," Journal of Arid Environments, vol. 68, no. 2, pp. 271-297, 2007.

[58] K. J. Wessels, F. van den Bergh, and R. J. Scholes, "Limits to detectability of land degradation by trend analysis of vegetation index data," Remote Sensing of Environment, vol. 125, pp. 10-22, 2012.

[59] P. Liu, L. Hao, C. Pan, D. Zhou, Y. Liu, and G. Sun, "Combined effects of climate and land management on watershed vegetation dynamics in an arid environment," Science of the Total Environment, vol. 589, pp. 73-88, 2017.

[60] D. Wu, X. Zhao, S. Liang et al., "Time-Lag effects of global vegetation responses to climate change," Global Change Biology, vol. 21, no. 9, pp. 3520-3531, 2015.

[61] X. Li and Y. Qu, "Evaluation of vegetation responses to climatic factors and global vegetation trends using GLASS LAI from 1982 to 2010," Canadian Journal of Remote Sensing, vol. 44, no. 4, pp. 357-372, 2019.

[62] Y. Malhi, J. T. Roberts, R. A. Betts, T. J. Killeen, W. Li, and C. A. Nobre, "Climate change, deforestation, and the fate of the Amazon," Science, vol. 319, no. 5860, pp. 169-172, 2008.

[63] J. Evans and R. Geerken, "Discrimination between climate and human induced dryland degradation," Journal of Arid Environments, vol. 57, no. 4, pp. 535-554, 2004.

[64] R. Quiroz, C. Yarlequé, A. Posadas, V. Mares, and W. W. Immerzeel, "Improving daily rainfall estimation from NDVI using a wavelet transform," Environmental Modelling and Software, vol. 26, no. 2, pp. 201-209, 2011.

[65] B. Qiu, W. Li, M. Zhong, Z. Tang, and C. Chen, "Spatiotemporal analysis of vegetation variability and its relationship with climate change in China," Geo-spatial Information Science, vol. 17, no. 3, pp. 170-180, 2014.

[66] R. G. Anderson, J. G. Canadell, J. T. Randerson et al., "Biophysical considerations in forestry for climate protection," Frontiers in Ecology and the Environment, vol. 9, no. 3, pp. 174-182, 2010.
[67] B. Chen, X. Zhang, J. Tao et al., "The impact of climate change and anthropogenic activities on alpine grassland over the Qinghai-Tibet plateau," Agricultural and Forest Meteorology, vol. 189-190, pp. 11-18, 2014. 